Aksiologiya: Jurnal Pengabdian Kepada Masyarakat

Vol.4, No.2, Agustus 2020 Hal 161 - 166

ISSN 2528-4967 (print) dan ISSN 2548-219X (online)

\title{
Pengabdian Masyarakat Penerapan PHBS di Sekolah
}

\author{
Yanik Purwanti ${ }^{1}$, Arief Wisaksono ${ }^{2}$, Andika Aliviameita ${ }^{3}$ \\ 1,2,3 Universitas Muhammadiyah Sidoarjo \\ e-mail: yanik1@umsida.ac.id', ariefWisaksono@umsida.ac.id², \\ andikaaliviameita@umsida.ac.id ${ }^{3}$
}

\begin{abstract}
ABSTRAK
Perilaku Hidup Bersih dan Sehat dibutuhkan siswa di sekolah agar terhindar dari berbagai penyakit. salah satunya adalah Cuci Tangan dengan sabun dan air bersih juga jajanan yang sehat. untuk mendukung hal tersebut perlu kerjasama yang baik antara pihak sekolah dan orang tua. siswa berpeluang besar untuk melaksanakan perilaku hidup bersih dan jajan sehat di sekolah tapi kenyataannya justru terbalik jajan di luar kantin sekolah, dengan resiko jajanan tidak terkontrol sekolah dan bisa mengancam kesehatan anak. Belum tersedianya tempat cuci tangan dan penyediaan air bersih di sekolah. Jajanan sehat bagi anak perlu diperkenalkan pada siswa juga wali murid sehingga ada kesinambungan kontrol yang baik antara pihak seolah dan wali murid. Maka, perlu diadakan Komunikasi, Edukasi dan Penyuluhan baik kepada siswa maupun wali murid. Dalam wadah parenting yang diadakan oleh TK dan MI Assasul Huda, Kepuh Kemiri Tulangan, Sidoarjo Sidoarjo bekerjasama dengan Universitas Muhammadiyah Sidoarjo. Komunikasi, Edukasi dan Penyuluhan yang diadakan pihak sekolah bekerjasama dengan Universitas Muhammadiyah Sidoarjo diharapkan terwujud perilaku Hidup Bersih dan sehat bagi siswa/siswi TK dan MI Assasul Huda, Kepuh Kemiri Tulangan, Sidoarjo dan kesadaran bagi siswa dalam menerapkan hidup Bersih dan Sehat (Cuci tangan paka sabun, pengunaan air bersih, jajanan sehat) sehingga terbentuk generasi sehat dan cerdas.
\end{abstract}

Kata Kunci: Perilaku Bersih dan Sehat

\section{Community Service Implementation of PHBS in Schools}

\begin{abstract}
Clean and Healthy Behavior is needed by students in schools to avoid various diseases. one of which is Handwashing with soap and clean water as well as healthy snacks. to support this it needs good cooperation between the school and parents. students have a great opportunity to practice clean living and healthy snacks at school, but the reality is actually reversed snacks outside the school canteen, with the risk of uncontrolled school snacks and can threaten children's health. The lack of a place to wash hands and provide clean water in schools. Healthy snacks for children need to be introduced to students as well as guardians of students so that there is continuity of good control between parties as if and guardians of students. So, it is necessary to hold Communication, Education and Counseling both to students and guardians of students. In a parenting container held by TK and MI Assasul Huda, Kepuh Kemiri Tulangan, Sidoarjo Sidoarjo in collaboration with Muhammadiyah University, Sidoarjo. Communication, Education and Counseling held by the school in collaboration with the University of Muhammadiyah Sidoarjo are expected to manifest Clean and healthy life behaviors for kindergarten and MI students Assasul Huda, Kepuh Kemiri Tulangan, Sidoarjo and awareness for students in implementing Clean and Healthy life soap, the use of clean water, healthy snacks) to form a healthy and smart generation.
\end{abstract}

Keywords: Clean and Healthy BehavTior

Copyright (C) 2020, Aksiologiya: Jurnal Pengabdian Kepada Masyarakat.

http://journal.um-surabaya.ac.id/index.php/Axiologiya/index

DOI: http://dx.doi.org/10.30651/aks.v4i2.2721 


\section{PENDAHULUAN}

Analisis Situasi TK dan MI Assasul Huda, Kepuh Kemiri Tulangan, Sidoarjo adalah lembaga pendidikan Swasta di Sidoarjo. Masa usia sekolah merupakan masa dimana anak belajar ketrampilan fisik dan membangun fisik yang sehat. Anak berkembang dari berbagai aspek yaitu berkembang fisiknya, baik motorik kasar maupun halus, berkembang aspek kognitif, aspek sosial dan emosional. Perkembangan motorik kasar potensial pesat pada anak usia dini hingga jenjang sekolah dasar.

Tugas perkembangan anak usia sekolah dasar adalah belajar mengembangkan kebiasaan untuk memelihara kesehatan dan kebersihan pribadi,Anaksudahbisamenyesuaikan diri dengan lingkungan dan dapat mengidentifikasi tentang kebutuhan kebersihan diri dan berperilaku hidup bersih dan sehat itu sangat penting bagi dirinya.

Aspek perilaku merupakan hal yang paling penting agar terwujudnya status kesehatan pribadi Perilaku Hidup Bersih dan Sehat sangat dibutuhkan pada siswa di sekolah dasar, agar terhindar dari berbagai penyakit.

Perilaku Hidup Bersih dan Sehat (PHBS) adalah sekumpulan perilaku yang dipraktekkan atas dasar kesadaran sebagai hasil pembelajaran, yang menjadikan seseorang keluarga, kelompok atau masyarakat mampu menolong dirinya sendiri (mandiri) di kesehatan dan berperan aktif dalam mewujudkan kesehatan.

Hidup Bersih dan Sehat salah satunya adalah memilih jajanan yang sehat di sekolah, untuk mendukung hal tersebut perlu kerjasama yang baik antara pihak sekolah, orang tua juga siswa dan lingkungan sekitar sekolah. TK dan MI Assasul Huda, Kepuh Kemiri Tulangan, Sidoarjo berada di lingkungan pedesaan pingiran Desa, dekat dengan perkebunan sayur, sehingga siswa berpeluang besar untuk melaksanakan perilaku hidup bersih dan jajan sehat di sekolah tapi kenyataannya justru terbalik jajan di luar kantin sekolah, dengan resiko jajanan tidak terkontrol sekolah dan bisa mengancam kesehatan anak, di tambah dengan belum tersediannya tempat cuci tangan dan tersediannya air bersih.

Kondisi saat ini banyak anakanak masih tidak cuci tangan saat akan makan Jajanan di tunjang dengan belum tersediannya tempat cuci tangan dan air bersih di sekolah dan jajananan nya belum tentu sehat. Ada temuan yang unik ada yang cuci tangan tapi dilakukan setelah makan saja. Maka, perlu diadakan Edukasi kepada siswa maupun wali murid. Dalam wadah parenting yang dilaksanakan oleh TK Assasul Huda, Kepuh Kemiri Tulangan, Sidoarjo.

Permasalah mitra yang diangkat pada program pengabdian masyarakat ini adalah tentang PHBS dan dukungan alat bantu penunjang terlaksanaanya PHBS di sekolah. Berkaitan dengan masalah disebutkan, maka perlu dicari sebuah solusi yang dapat mengatasi masalah-masalah tersebut secara efektif.

Tujuan dan manfaat dari kegiatan 
pengabdian ini adalah memberikan solusi atas permasalahan yang dihadapi oleh Mitra yakni dengan Memberikan KIE tentang PHBS dan mengibabahkan alat bantu penunjang terlaksanaanya PHBS di sekolah.

\section{METODE PELAKSANAAN}

Tahapan-tahapan yang akan dilakukan dalam menyelesaikan permasalahan mitra adalah sebagai berikut.

1. Observasi lapangan

2. Identifikasi permasalahan dan kelemahan mitra

3. Penawaran solusi pada mitra

4. Penyuluhan/KIE tentang PHBS

5. Pelatihan Penerapan

6. Evaluasi dan monitoring

Metode pelaksanaan merupakan landasan atau acuan agar proses dalam program pengabdian kepada masyarakat ini berjalan secara sistematis, terstruktur, dan terarah. Setelah proses observasi lapangan dan identifikasi permasalahan dilakukan, maka akan dilakukan perancangan solusi. Selanjutnya solusi yang menjadi yang telah direncanakan akan ditawarkan kepada mitra. Metode yang akan digunakan dalam program ini ditunjukkan pada Gambar 1 .
Observasi merupakan tahap awal yang harus dilakukan dalam program ini. Dengan adanya observasi ini akan diketahui keadaan nyata perlaku hidup bersih dan sehat pada mitra sekaligus sebagai bahan awal untuk proses lanjutan dan bisa menentukan apa saja kebutuhan mitra serta pola seperti apa pelaksannannya

Pemberian Informasi dan edukasi tentang perilaku hidup bersih dan sehat adalah proses penanaman kebiasaan yang perlu dlakukan berulag-ulang yang akhirnya menjadi kebiasaan.

Setelah dilakukan penyuluhan atau pemberian informasi dan edukasi selanjutnya perlu dilakukan monitoring dan evaluasi dari hasil penyuluhan tersebut agar konsistensi pelaksanaan terjaga sehingga menghasilan kebiasaan baik terutama perilaku hidup bersih dan sehat pada siswa.

Dalam program pengabdian pada masyarakat ini, mitra diharapkan dapat berpartisipasi. Mitra akan berpartisipasi dalam menyediakan tempat penyuluhan dan pelatihan juga monitoring pelaksanaan kebiasaan perilaku bersih sehat pada siswa. Selain itu, mitra akan mengikuti

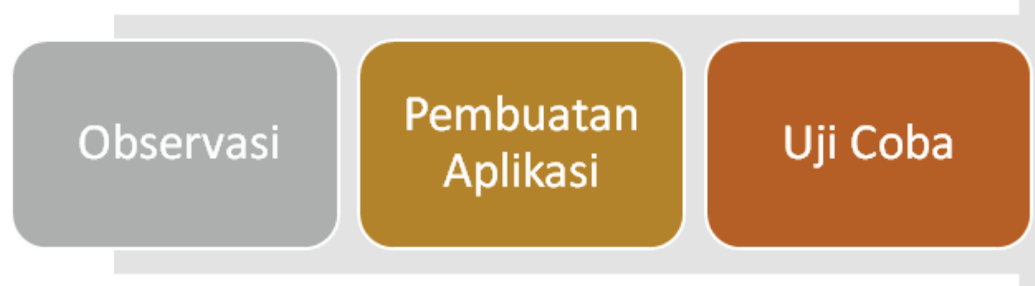

\section{aplikasi}

berbasis web

Gambar 1. Metode Pelaksanaan Program 
pelatihan cara penerapan perilaku hidup bersih dan sehat.

Evaluasi dilakukan dengan cara memantau secara rutin atas kebiasaan dan kemauan untuk menggunakan sarana yang telah disediakan secara mandiri oleh pihak sekolah, selanjutnya akan selalu diadakan laporan hasil evaluasi melalui program parenting yang dilaksakan setiap periode 1 tahun sekali sekaligus sebagai acara silaturahim antara guru dan para wali murid.

Diharapkan dari program ini ada keberlanjutan program dengan melakukan penambahan sarana lain seperti program kantin sehat dan monitoring PHBS sekolah sehingga program bisa berkesinambungan.

\section{HASIL DAN PEMBAHASAN}

Setelah dilakukan pengabdian masyarakat hasil yang didapatkan adalah sebagai berikut.

1. Telah Terpasang sarana dan prasarana penunjang PHBS berupa:

a. Tandon penampung air yang difungsikan sebagai penyiman cadangan air yg sewaktu-waktu bisa langsung digunakan oleh semua komponen sekolah.

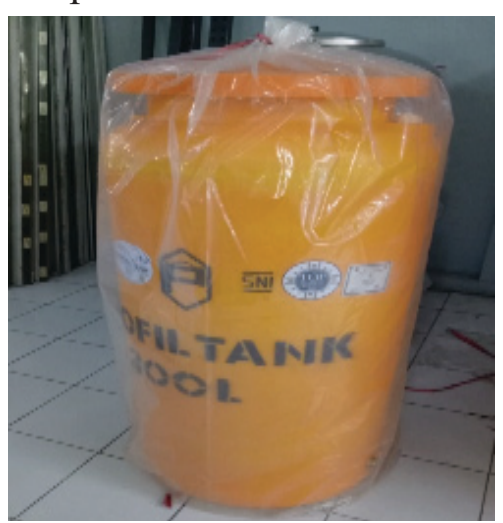

Hibah satu set tandon yang dipasang langsung bersama penyangganya

b. Saluran air bersih dari sumur menuju halaman.

c. Wastafel yang difungsikan untuk media cuci tangan.

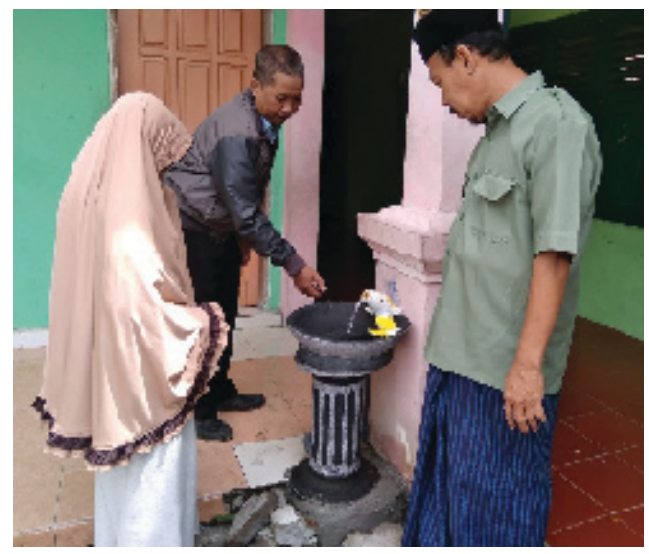

d. Tempat sampah, Pemasangan tempat sampah dilakukan pada beberapa titik yang mudah dijangkau oleh siswa dan semua komponen warga sekolah. dengan adanya tempat sampah ini semua otomatis tidak lagi membuang sampah sembarangn.

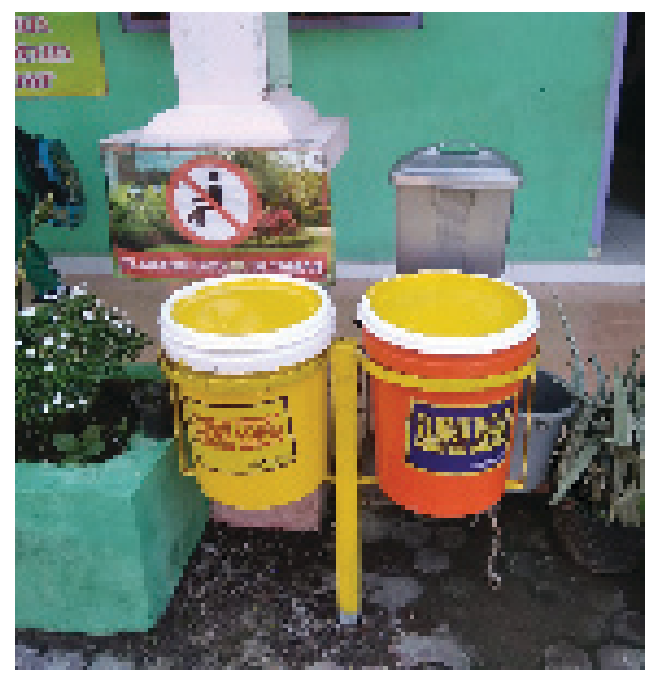

e. Perilaku bersih dan sehat dari siswa -siswi Madrasah Ibtidaiyah (MI) dan Taman Kanak-Kanak. 


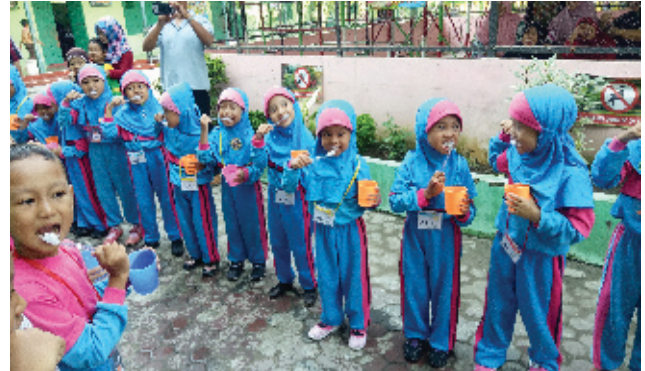

f. Perilaku bersih dan sehat para orang tua yang selalu mengantarkan putra-putrinya yang sedang bersekolah di TK karena selain sosiaisasi dari para pendidik, dan anak yang sudah mendapatkan pelatihan tentang Perilaku Hidup Bersih dan Sehat.

g. Parenting orang tua wali siswa tentang PHBS dan ajanan sehat . parenting adalah bagian dari implementasi atau sosialisasi usaha-usaha yang dilaksanakan untuk melaksanakan rencana dan kebijaksanaan yang telah dirumuskan dan ditetapkan pada pihak terkait

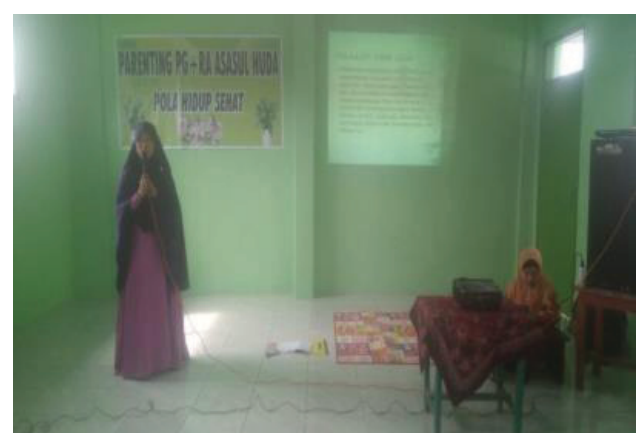

Kegiatan parenting tentan PHBS

h. Perilaku selalu hemat energy. Dengan terpasangnya tendon dan saluran air ini menimbulkan kebiasaan untuk tidak selalu menyalakan pompa sewaktu waktu. Hasil akhirnya menghemat biaya listrik.

i. Perilaku hemat air. Hal ini terjadi dikarenakan kebiasaan untuk menggunakan air pada kran, dengan cara ini warga sekolahan akan terbiasa menggunakan air sesuai aliran yang ada tidak seperti ketika menggunakan gayung untuk mngambil air, ketika cuci tangan.

j. Pemberian Poster berisi tentang ajakan Berperilaku Hidup Bersih dan Sehat adalah sarana prasarana yang mendukung penanaman karakter siswa tentang cara menggosok gigi, cara mencuci tangan yang benar, dan poster membuang sampah pada tempatnya.

\section{SIMPULAN}

Penerapan Perilaku Hidup Bersih dan Sehat bisa di laksanakan dengan baik setelah di berikan KIE, Alat pendukung seperti poster dan tempat cuci tangan juga tempat sampah, hal yang terlihat dan tidak kalah penting adalah antusias siswa dan siswi di kedua mitra dalam menerapkan Perilaku Hidup Bersih dan Sehat (PHBS) disekolah.

\section{DAFTAR PUSTAKA}

Eko Sucipto Dan Suryanto. Perilaku Et Al., "Gor Fik Uny Oleh :," Vol. Xiv, No. 1, 2015.

E. Burhaein, "Aktivitas Fisik Olahraga Untuk Pertumbuhan Dan Perkembangan Siswa Sd," Indones. J. Prim. Educ., Vol. 1, No. 1, P. 51, 2017. 
Kementerian Kesehatan, Pedoman Pembinaan Perilaku Hidup Bersih Dan Sehat: Katalog Dalam Terbitan Kementerian Kesehatan Ri. 2011.

M. A. Makhsyari, D. E. Handayani, And S. A. Prasetyo, "Penerapan Perilaku Hidup Bersih Dan Sehat Dalam Menanamkan Nilai Karakter Siswa," Vol. 5, Pp. 99-111.

N. Gaveni, "Pelaksanaan Program Parenting Bagi Orangtua Dalam Menumbuhkan Perilaku Keluarga Ramah Anak," Pp. 1-11, 2012.

S. N. Lestari, E. Hartati, And M. Supriyono, "Gambaran Perilaku Hidup Bersih Dan Sehat ( Phbs ) Di Sekolah Pada Siswa Sd Kembangarum 02 Semarang Barat," Pp. 1-10, 2016.

S. Yudo, "Upaya Penghematan Air Bersih Di Gedung Perkantoran Water Saving Efforts In Offices Building Case Study: Water Saving In Bppt Office Building," J. Teknol. Lingkung., Vol. 19, No. 1, Pp. 97-106, 2018.

T. Nurbiyati Et Al., "Pentingnya Memilih Jajanan Sehat Demi Kesehatan Anak," Inov. Dan Kewirausahaan, Vol. 3, No. 3, Pp. 192-196, 2014.

W. Universitas Gadjah Mada. Fakultas Psikologi., A. F. Citra, M. Saputra, M. Damariyanti, A. M. Ayuningsih, And M. M. Siahay, "Jurnal Psikologi.," J. Psikol., Vol. 44, No. 2, Pp. 139 - 152, 2017.

Y.Andriansyah And D. N. Rahmantari, "Penyuluhan Dan Praktik Phbs (Perilaku Hidup Bersih Sehat) DalamMewujudkan Masyarakat Desa Peduli Sehat," J. Inov. Dan Kewirausahaan, Vol. 2, No. 1, Pp. 45-50, 2013.

Y. N. Abidah And A. Huda, "Pelaksanaan Program Perilaku Hidup Bersih Dan Sehat ( Phbs
) Di Sekolah Luar Biasa," Vol. 4, No. November, Pp. 87-93, 2018 . 